\title{
Intracerebral hemorrhage in the context of cerebral amyloid angiopathy and varied time of onset of cerebral venous thrombosis: a case report
}

\author{
Tadeusz A. Mendel ${ }^{1}$, Beata Błażejewska-Hyżorek¹, Grażyna M. Szpak², Tomasz Stępień², Eliza Lewandowska², \\ Sylwia Tarka ${ }^{2,3}$, Iwona Kurkowska-Jastrzębska ${ }^{1}$, Teresa Wierzba-Bobrowicz ${ }^{2}$ \\ ${ }^{1} 2^{\text {nd }}$ Department of Neurology, Institute of Psychiatry and Neurology, Warsaw, ${ }^{2}$ Department of Neuropathology, \\ Institute of Psychiatry and Neurology, Warsaw, ${ }^{3}$ Department of Forensic Medicine, Medical University of Warsaw, Warsaw, Poland
}

\begin{abstract}
In patients with cerebral venous thrombosis (CVT) the incidence of intracerebral hemorrhage (ICH) is estimated at about $37 \%$ and subarachnoid hemorrhage (SAH) at $1 \%$ of patients. A case with coincident occurrence of ICH, SAH and CVT in a patient with cerebral amyloid angiopathy (CAA) is reported.

A 79-year-old woman was admitted to the Neurological Department after the occurrence of generalized seizures, the first in her life. On admission she was unconscious with right hemiparesis and deviation of eyes to the left. On computed tomography (CT) scan many hemorrhagic infarcts were present in the frontal, parietal, temporal and left occipital lobes. Angio-CT revealed thrombosis in the right transverse sinus, right internal carotid vein and superior sagittal sinus. Her state slowly deteriorated. She died after 6 days. Neuropathologically, many hemorrhagic infarcts were observed in cortical regions in the vicinity of veins with thrombosis and in the white matter. The varied time of onset of thrombosis of the right sigmoid sinus, right superior petrosal sinus, superior sagittal sinus, right transverse sinus and the proximal part of the right internal carotid vein was confirmed. cerebral amyloid angiopathy in brain vessels was diagnosed.

Subarachnoid hemorrhage is a very uncommon presentation of CVT and may coexist with CAA. We can only speculate that CAA may have an effect on vein destruction and can promote cerebral vein thrombosis and in consequence also predispose to intracerebral hemorrhage and subarachnoid hemorrhage. The most probable cause of extensive thrombosis was a coagulation disorder.
\end{abstract}

Key words: cerebral amyloid angiopathy, cerebral venous thrombosis, intracerebral hemorrhage, $\beta$-amyloid.

\section{Introduction}

Cerebral venous thrombosis (CVT) is the occlusion/thrombosis of the veins and/or venous sinuses in the brain [19]. Cerebral venous thrombosis was first described in 1825 [20]. In patients with CVT, the incidence of cerebral hemorrhage was reported to be about $37 \%$ and subarachnoid hemorrhage (SAH) was found in $1 \%$ of patients [2,3,5]. Cerebral venous thrombosis can be difficult to diagnose because of the wide spectrum of clinical manifestations, so 
it requires a high index of suspicion [3,15,23]. Subarachnoid hemorrhage mostly involves the cerebral convexity and spares the basal cisterns and skull base $[1,18]$. The transverse sinus, sigmoid sinus, and concomitant sinus and vein are the most common locations of venous thrombosis $[6,25]$. The coexistence of intracerebral hemorrhage $(\mathrm{ICH}), \mathrm{SAH}$ and CVT is also possible, especially in patients with diagnosed cerebral amyloid angiopathy (CAA) [11,22]. Cerebral amyloid angiopathy occurs sporadically in the elderly population or in familiar forms of Alzheimer's disease, and it is characterized by insoluble deposition of $\beta$-amyloid peptides within vessels of the central nervous system. It is a progressive disease $[6,7,12]$. Cerebral venous thrombosis is a potentially serious, but treatable condition, and its outcome depends on early diagnosis and management. The majority of patients improved after applying anticoagulant therapy. It should be remembered that CAA should be excluded in such cases [4].

\section{Case report}

A 79-year-old woman was admitted to the Neurological Department after the sudden occurrence of generalized seizures, the first in her life. She had hypothyroidism, glaucoma and nicotinism. On admission she was unconscious with right hemiparesis and with deviation of eyes to the left. On computed tomography (CT) scan many hemorrhagic infarcts were present in the frontal, parietal, temporal and left occipital lobes (Fig. 1). Angio CT revealed thrombosis in the right transverse sinus, the right internal carotid vein and the superior sagittal sinus. The patient's status improved after $2 \mathrm{~h}$ of hospitalization. She was conscious, with right hemiplegia, global aphasia and deviation of eyes to the left. Unfortunately, after the next few hours her state slowly deteriorated; she was unconscious with low pressure $60 / 40 \mathrm{mmHg}$, bradycardia $45 / \mathrm{min}$, and GCS score of 3 points. She had pulmonary infections with high temperature with D-dimers $40325 \mathrm{ng} / \mathrm{ml}(\mathrm{N}=0-500 \mathrm{ng} / \mathrm{ml})$, increased activated partial thromboplastin time (APTT) to $45 \mathrm{sec}$ onds ( $N=26-36$ seconds) and elevated CRP level of $111 \mathrm{mg} / \mathrm{l}(\mathrm{N}=0-5 \mathrm{mg} / \mathrm{l})$. She died after 6 days of hospitalization.

The macroscopic brain examination revealed many hemorrhagic infarcts in cortical regions in the vicinity of thrombotic veins, and many hemorrhages were observed in the white matter (Fig. 2, Fig. 4). Also the varied time of onset of thrombosis lasting in our opinion two or three days in the superior sagittal sinus in the right sigmoidal sinus, right superior petrosal sinus, right transverse sinus and proximal part of the right internal carotid vein was confirmed (Figs. 3 and 5-8).

Microscopic examination of the thrombus revealed that it consisted of erythrocytes, fibrin, and fibroblasts and thrombotic occlusion in the cerebral artery (Figs. 8 and 9). Cerebral amyloid angiopathy

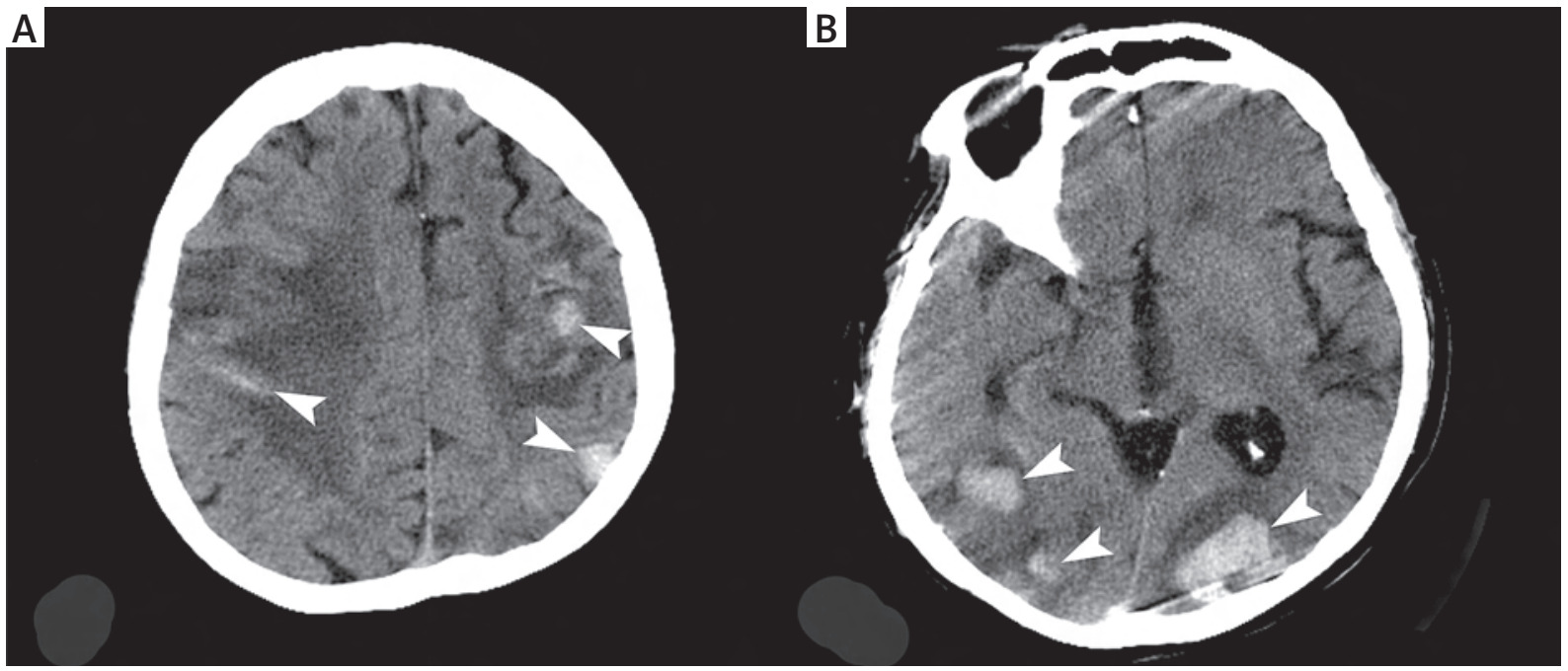

Fig. 1. The hemorrhagic infarcts localized in the frontal, parietal (A), localized in the temporal and occipital lobes (arrow heads, CT scan) (B). 


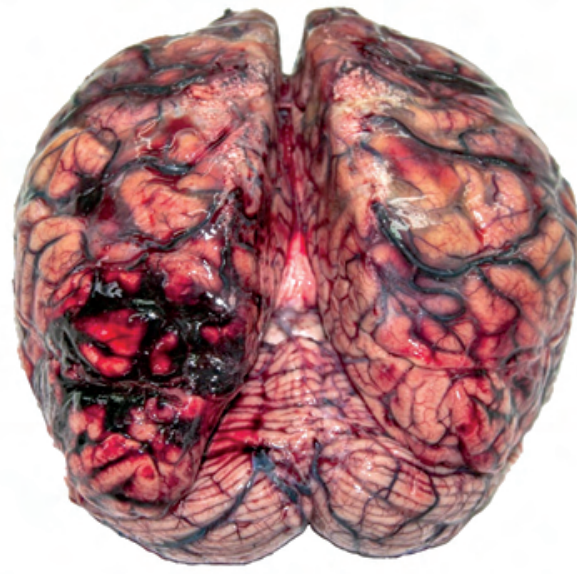

Fig. 2. Macroscopic picture of brain with many hemorrhagic infarcts in cortical regions in the vicinity of veins with thrombosis.

in the brain vessels and atherosclerosis grade III in the vessels of circus Willis were diagnosed (Fig. 10).

Ultrastructural examination revealed the presence of small arterioles with degenerating vascular smooth muscle cells (VSMCs) and amyloid fibers (A) in the thickened basement membrane (BM) (Figs. 11 and 12).

\section{Methods}

The brain was fixed in buffered formalin. The brain specimens were paraffin embedded and stained histologically with H\&E, PAS, Congo Red and Mallory methods and immunohistochemically with anti-A $\beta$ 1-40 (Serotec 1 : 250) and anti-A $\beta$ 1-42 (Serotec 1 : 250). The grade of CAA was assessed according to Vonsattel [24]. For ultrastructural analysis, a small fragment of the brain was taken from a paraffin block. After deparaffinizing and washing in tap water, brain specimens were fixed in $2.5 \%$ glutaraldehyde in cacodylate buffer and postfixed in $2 \%$ osmium tetroxide in the same buffer. They were then dehydrated and embedded in Epon. Ultrathin sections stained with uranyl acetate and lead citrate were examined using an Opto DPS 109 electron microscope.

\section{Discussion}

The spectrum of clinical presentation of CVT ranges from headache within papilledema to focal deficit, seizures and coma [2,25]. Sudden onset of diseases and generalized seizures can both be
A

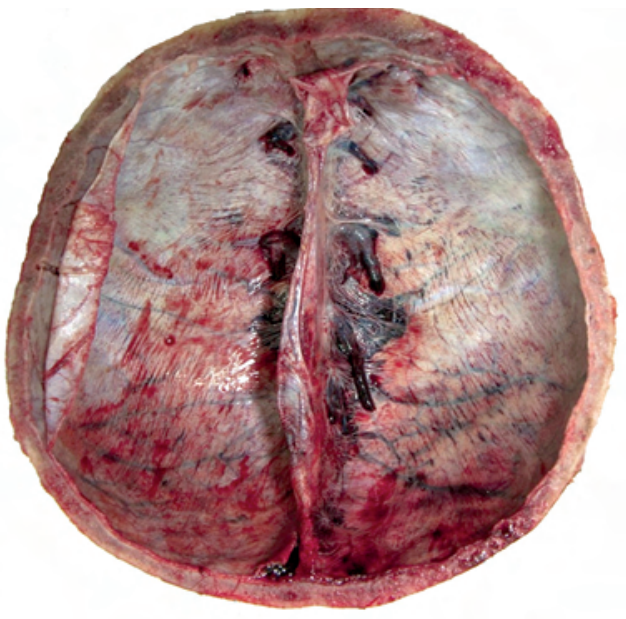

B

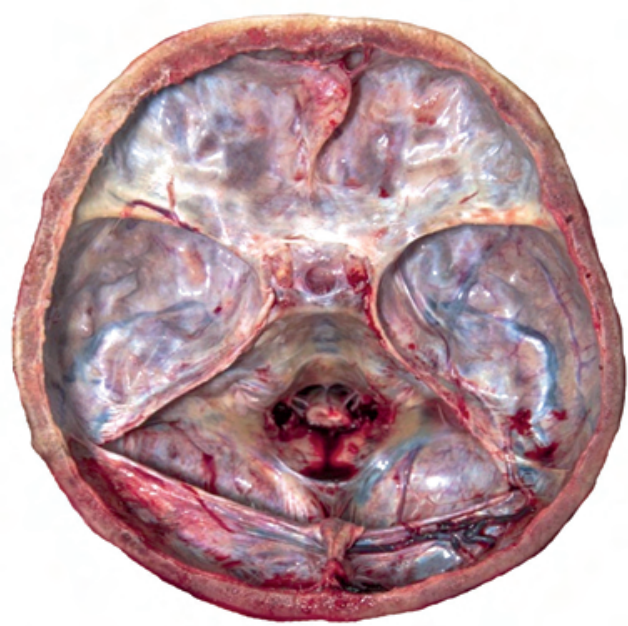

Fig. 3. Macroscopic picture of vein sinus of dura mater.

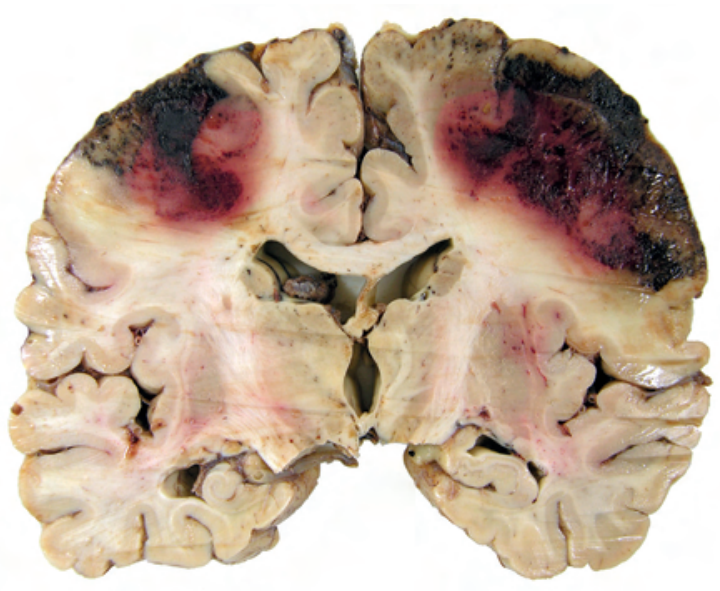

Fig. 4. Macroscopic picture of hemorrhagic infarcts localized in cortical regions. 
A

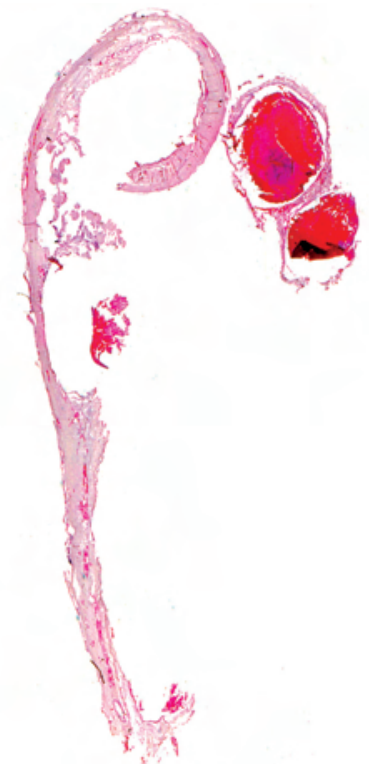

B

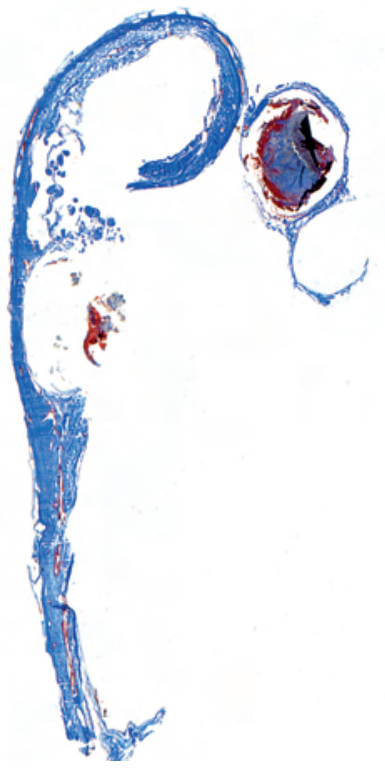

Fig. 5. Veins with thrombosis entering the superior sagittal sinus. HE (A), Mallory (B), Lupe.

A

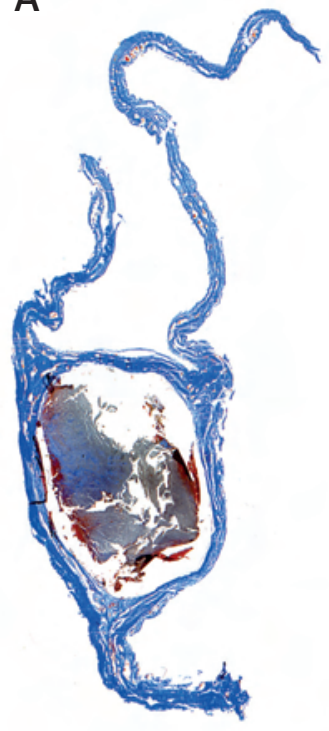

B

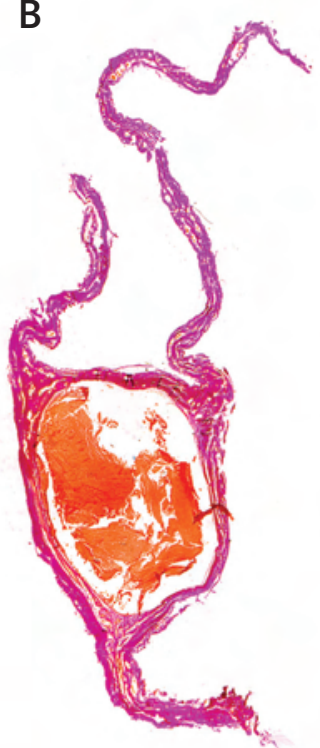

C

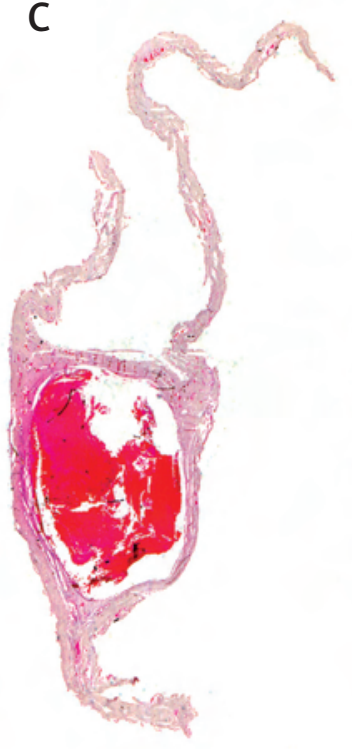

D

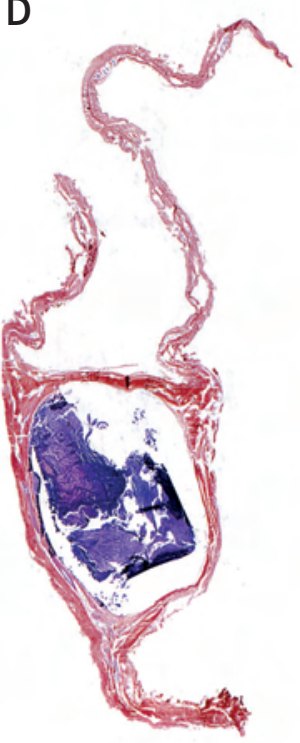

Fig. 6. Sinuses confluence with thrombus inside. Mallory (A), Van Gieson (B), HE (C), PTAH (D). Lupe.

suspected as ICH and CVT [23]. In older patients with CAA more often altered consciousness, outcome and prognosis are worse [2,5].

Cerebral amyloid angiopathy was diagnosed neuropathologically, but it can be suspected clinically according to the Boston criteria of CAA, which include the presence of multiple hemorrhages, age more than 55 years and absence of other causes of hemorrhage [9]. Our CAA case was diagnosed neuropathologically according to the Boston criteria [9].

Treatment of CVT in patients with CAA can be symptomatic and etiologic in some cases [2,4].

There are some cases published previously that indicate the possibility of coincidence of $\mathrm{ICH}, \mathrm{SAH}$ and CVT occurrence in patients with diagnosed CAA $[10,11,15]$. Cerebral amyloid angiopathy can also be 
A

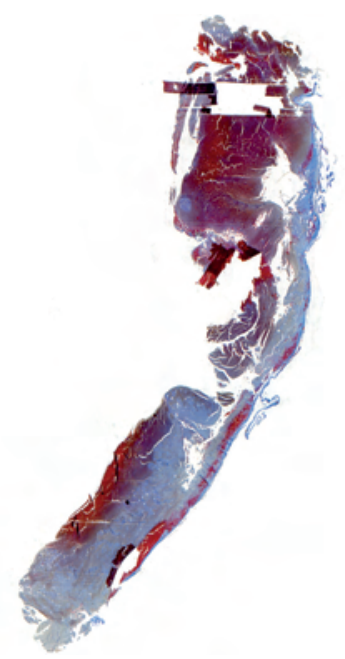

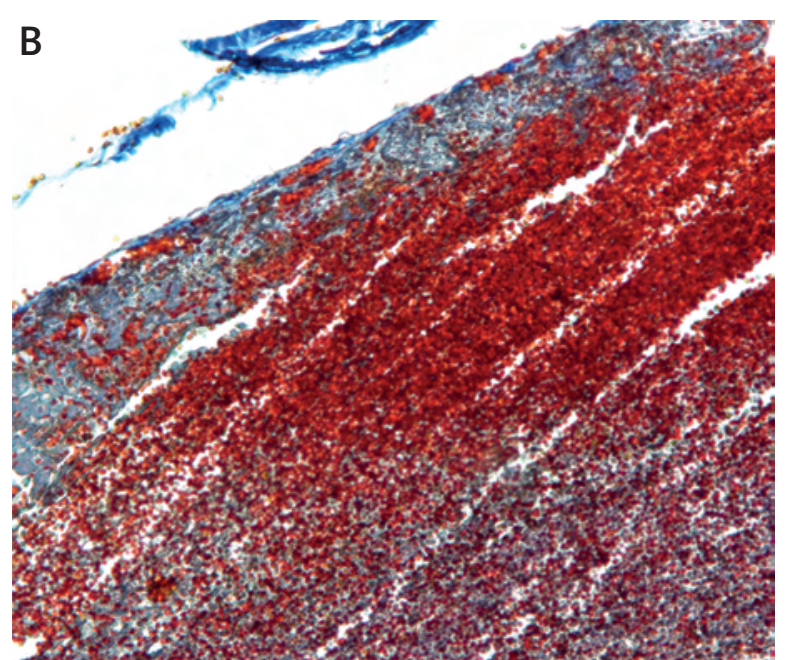

Fig. 7. Macroscopic and microscopic picture of sigmoidal sinus thrombosis . Mallory (A), (B) ×100.
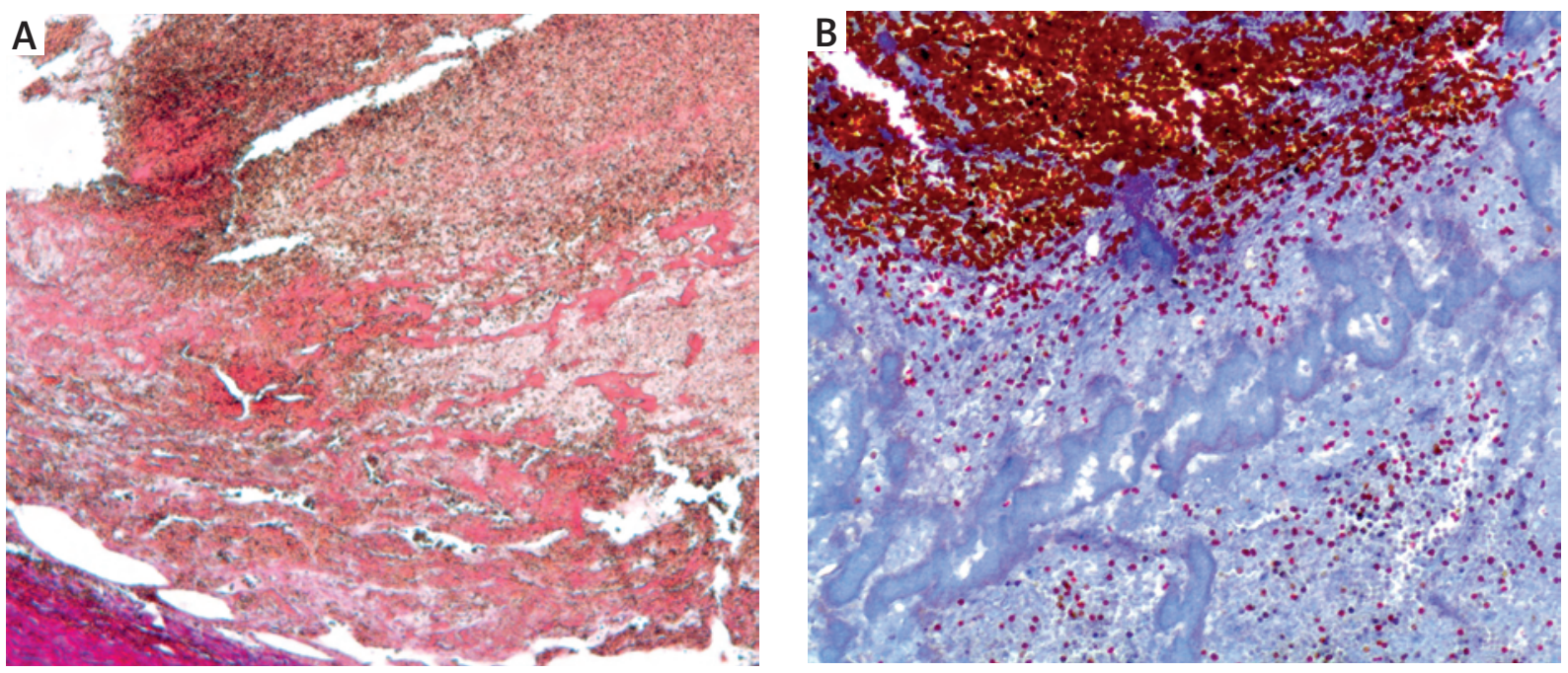

Fig. 8. Thrombus: consisted of erythrocytes, fibrin and fibroblast. PAS (A) $\times 25$, Mallory (B) $\times 100$.

manifested as a brain tumor and coexist with atherosclerosis [8,13].

Sometimes it is difficult to assess whether the location of a lesion may indicate arterial or vein origin of the hemorrhagic infarct. In our case the localized presence of subarachnoid blood in the cerebral convexities, sparing the basal cisterns, may suggest venous SAH because of occlusion of a local vein or venous sinus.

In our earlier study $\beta$-amyloid in veins was found in $78 \%$ of patients with CAA and ICH [14]. According to both the Vonsattel and Mountoy scales, severe and moderate changes were dominating in that group of patients $[16,24]$. We concluded that veins

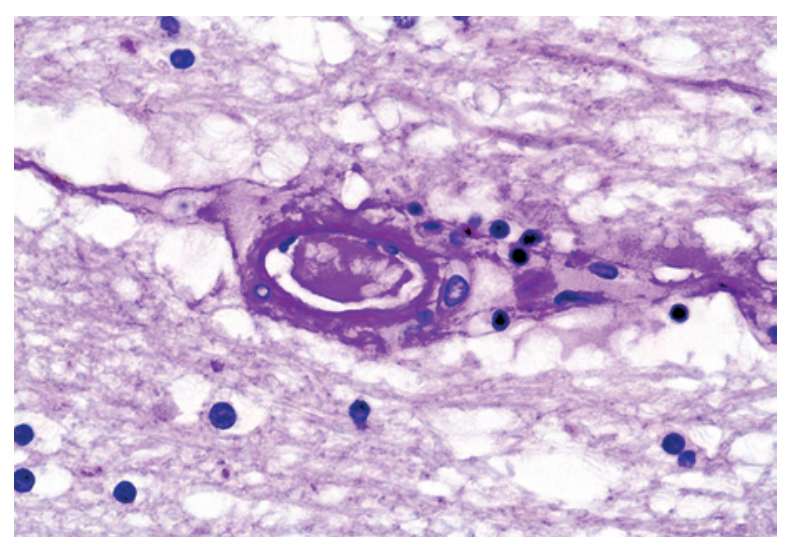

Fig. 9. Thrombotic occlusion in cerebral artery. PAS $\times 400$. 

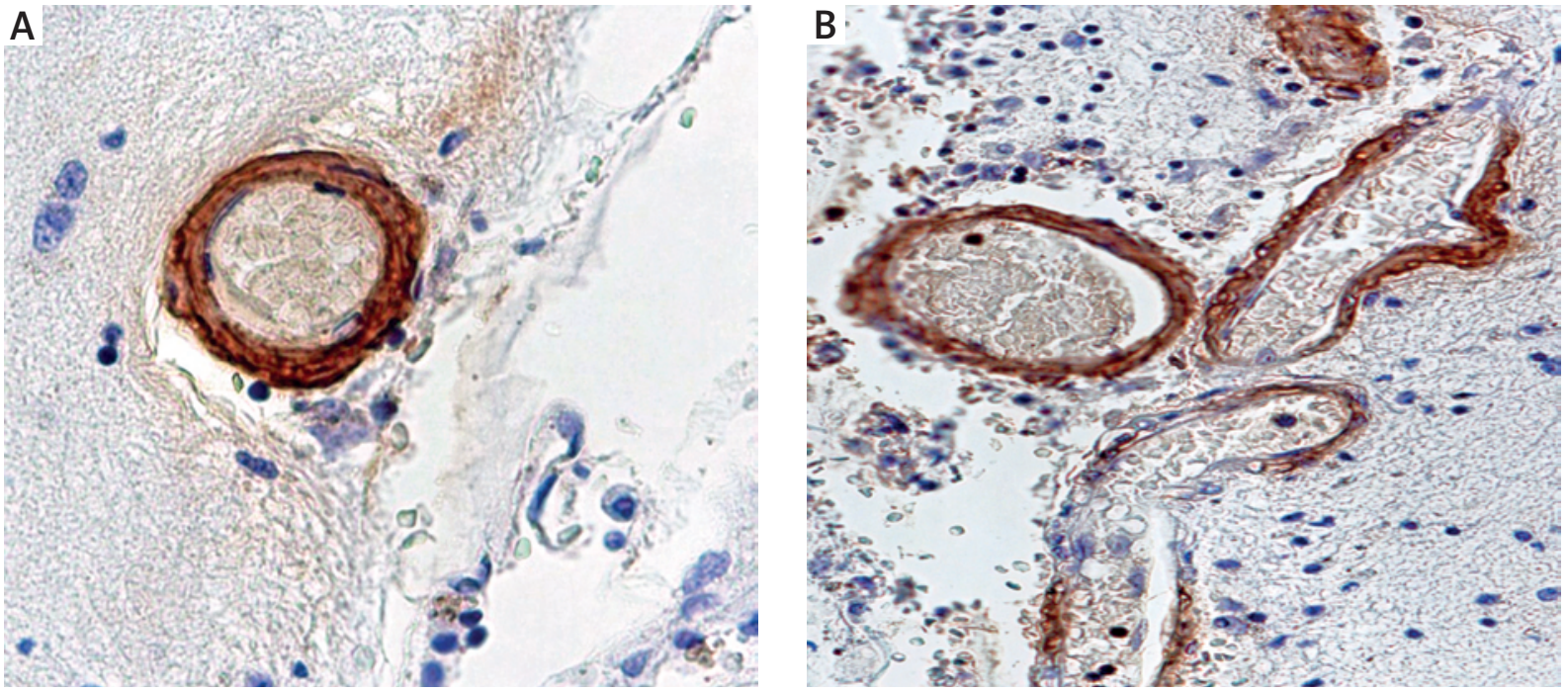

Fig. 10. Cerebral amyloid angiopathy occipital cortex $A \beta$ deposits in the wall of vessels. A) In artery vessels, $B$ ) in veins. Anti-A $\beta \times 200$. Moderate and severe amyloid angiopathy according to Vonsattel scale in the vessels were found in the cerebral vessels using $A \beta$ staining.

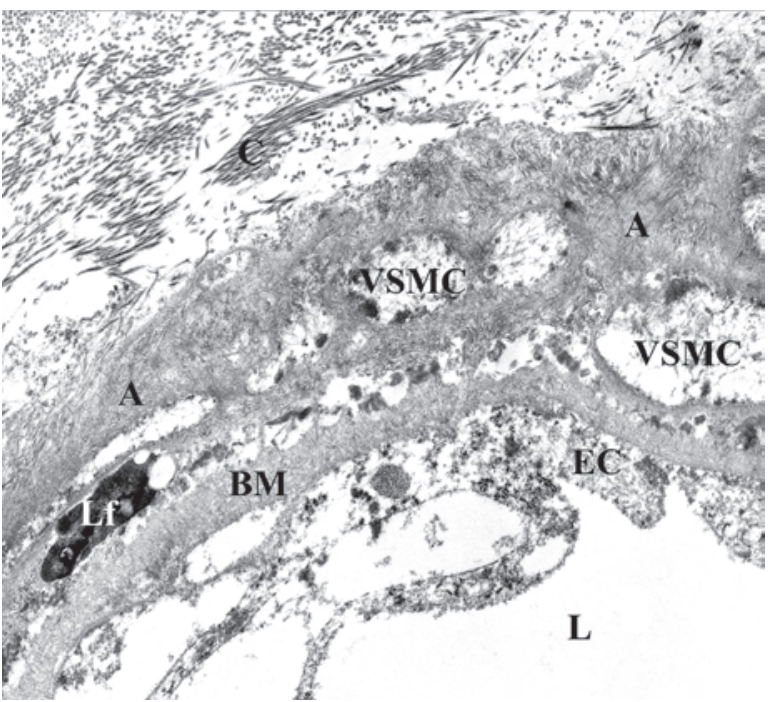

Fig. 11. Small arteriole with degenerating vascular smooth muscle cells (VSMCs), amyloid fibers (A) in thickened basement membrane (BM). Numerous collagen fibers (C) in the periphery of arteriole wall. $L$ - lumen, LF - lipofuscin. Orig. magn. $\times 7000$.

are not so rarely involved in $\beta$-amyloid in intracerebral hemorrhage and that cerebral amyloid angiopathy is localized in brain veins more often than previously suspected [14]. We confirm that $\beta$-amyloid accumulates in the venous system. Veins may play

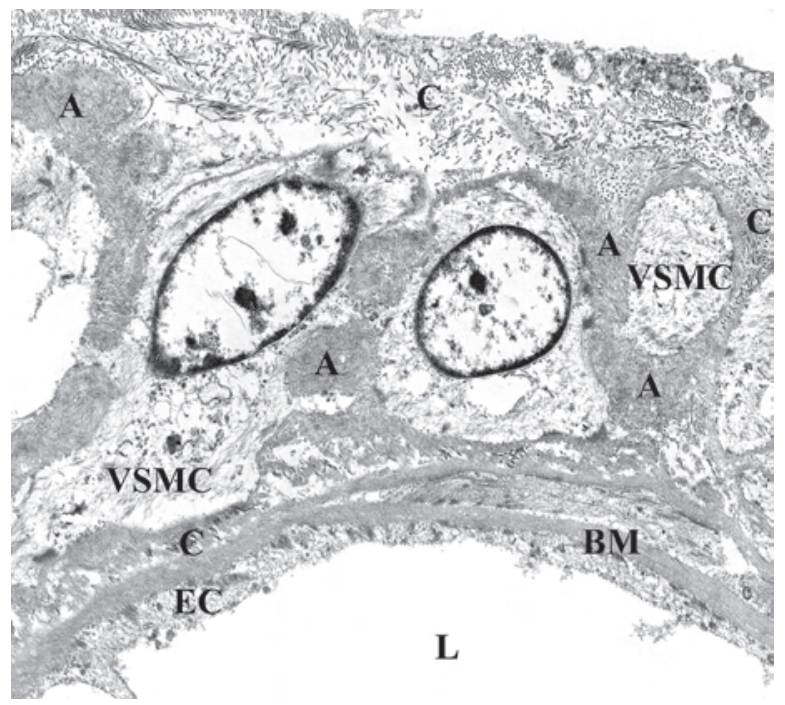

Fig. 12. Focal deposits of amyloid fibers (A) in thickened basement membrane (BM) between smooth muscle cells (VSMCs) and numerous collagen fibers (C) in periphery of arteriole wall. $\mathrm{L}-$ lumen. Orig. magn. $\times 4400$.

an important role in the elimination of $\beta$-amyloid and not only as perivascular drainage [14].

$\beta$-amyloid clearance in the central nervous system consisted of the "glymphatic pathway" involving the para-arterial cerebrospinal fluid (CSF) influx 
route, para-venous intestinal fluid (ISF) efflux rote, and convective bulk fluid flux [17,21].

It is known that CAA involves small cerebral and leptomeningeal vessels but not sinuses or such relatively large vessels as the internal carotid vein. Cerebral amyloid angiopathy destroys mainly vascular media and adventitia with relative sparing of endothelial cells.

We can only speculate that CAA may have an effect on vein destruction and can promote cerebral vein thrombosis and in consequence also predispose to intracerebral hemorrhage and subarachnoid hemorrhage. In our case the most probable cause of extensive thrombosis was a coagulation disorder, because the level of D-dimers was very high and increased APTT.

\section{Disclosure}

\section{Authors report no conflict of interest.}

\section{References}

1. Benabu Y, Mark L, Daniel S, Glikstein R. Cerebral venous throm bosis presenting with subarachnoid hemorrhage. Case report and review. Am J Emerg Med 2009; 27: 96-106.

2. Bousser MG, Ferro JM. Cerebral venous thrombosis: an update. Lancet Neurol 2007; 6: 162-170.

3. Breteau G, Mounier-Vehier F, Godefroy O, Gauvrit JY, Mackowiak-Cordoliani MA, Girot M, Bertheloot D, Hénon H, Lucas C, Leclerc X, Fournier F, Pruvo JP, Leus D. Cerebral venous thrombosis 3-year clinical outcome in 55 consecutive patients. J Neurol 2003; 250: 29-35.

4. Einhäupl K, Stam J, Bousser MG, de Bruijn SF, Ferro JM, Martinelli I, Masuhr F. EFNS guideline on the treatment of cerebral venous and sinus thrombosis in adult patients. Eur J Neurol 2010; 17: 1229-1235.

5. Ferro JM, Canhäo P, Stam J, Bousser MG, Barinagarrementeria F, ISCVT Investigators. Prognosis of cerebral vein and dural sinus thrombosis: results of the International study of Cerebral Vein and Dural Sinus Thrombosis (ISCVT). Stroke 2004; 35: 664-670

6. Girot M, Ferro JM, Canhäo P, Stam J, Bousser MG, Barinagarrementeria F, ISCVT Investigators. Predictors of outcome in patients with cerebral venous thrombosis and intracerebral hemorrhage. Stroke 2007; 38: 337-347.

7. Johnson AW, Zipfel GJ, Han HB. Cerebral amyloid angiopathy: perspectives on cerebrovascular dysfunction. J Neurol Disord 2013; 2: e108.

8. Karbowniczek A, Wierzba-Bobrowicz T, Mendel T, Nauman P. Cerebral amyloid angiopathy manifestated as a brain tumor. Clinical and neuropathological characteristics. Folia Neuropathol 2012; 50: 194-200.
9. Knudsen KA, Rosand J, Karluk D, Greenberg SM. Clinical diagnosis of cerebral amyloid angiopathy: Validation of the Boston Criteria. Neurology 2001; 56: 537-539.

10. Komurcu HF, Okundu S, Ercan K, Anlar O. A case of cerebral amyloid angiopathy associated with cerebral venous thrombosis. Int J Res Med Sci 2014; 2: 1141-1143.

11. Mendel T. Mózgowa angiopatia amyloidowa. IPiN, Warszawa 2013.

12. Mendel TA, Wierzba-Bobrowicz T, Lewandowska E, Stępień T, Szpak GM. The development of cerebral amyloid angiopathy in cerebral vessels. A review with illustrations based upon own investigated post mortem cases. Pol J Pathol 2013; 64: 260-267.

13. Mendel TA, Wierzba-Bobrowicz T, Stępień T, Szpak GM. The association between cerebral amyloid angiopathy and atherosclerosis in patients with intracerebral hemorrhages. Folia Neuropathol 2013; 51: 243-249.

14. Mendel T, Wierzba-Bobrowicz T, Stępień T, Szpak GM. $\beta$-amyloid deposits in veins in patients with cerebral amyloid angiopathy and intracerebral hemorrhage. Folia Neuropathol 2013; 51: 120126.

15. Morris JG, Fisher M, Carandang RA. Cortical vein thrombosis as a mimic for isolated cortical subarachnoid hemorrhage and transient ischemic attack. Case Rep Neurol 2010; 2: 63-68.

16. Mountjoy CQ, Tomlinson BE, Gibson PH. Amyloid and senile plaques and cerebral blood vessels. J Neurol Sci 1982; 57: 89-103.

17. Nedergaard M. Neurosciences. Garbage truck of the brain. Sciences 2013; 340: 1529-1530.

18. Panda S, Prashantha DK, Shankar SR, Nagaraja D. Localized convexity subarachnoid haemorrhage - a sign of early cerebral venous sinus thrombosis. Eur J Neurol 2010; 17: 1249-1256.

19. Pangmoragot J, Saposnik G. Intracerebral hemorrhage from cerebral venous thrombosis. Curr Atheroscler Rep 2012; 14: 382-389.

20. Ribes MF. Des recherché faites sur la phlebite. Rev Med Franc Etrang 1825; 3: 5-41.

21. Saito S, Ihara M. New therapeutic approaches for Alzheimer's disease and cerebral amyloid angiopathy. Front Aging Neurosci 2014; 6: 1-11.

22. Sharma S, Sharma N, Yeolekar ME. Acute subarachnoid hemorrhage as initial presentation of dural sinus thrombosis. J Neurol Rural Pract 2010; 1: 23-25.

23. Urban PP, Müller-Forell W. Clinical and neuroradiological spectrum of isolated certical vein thrombosis. J Neurol 2005; 252: 1476-1481.

24. Vonsattel JPG, Myers RH, Hedley-Whyte ET, Ropper AH, Bird ED, Richardson EP. Cerebral amyloid angiopathy without and with cerebral hemorrhage: A comparative histological study. Ann Neurol 1991; 30: 637-649.

25. Wasay M, Kojan S, Dai Al, Bobustuc G, Sheikh Z. Headache in cerebral venous thrombosis: incidence, pattern and location in 200 consecutive patients. J Headache Pain 2010; 11: 137-139. 